Journal of Electronics and Informatics (2020)

Vol.02/ No. 02

Pages: 137-147

http://www.irojournals.com/iroei/

DOI: https://doi.org/10.36548/jei.2020.2.005

\title{
Artificial Intelligence Based Distribution System Management and Control
}

\author{
Dr. D. Nirmal \\ Associate Professor, \\ Department of Electrical sciences, \\ Karunya University, Karunya Nagar, \\ Coimbatore, Tamil Nadu, India 641114. \\ Email id: nirmal@karunya.edu
}

\begin{abstract}
The electrical transmission and distribution systems are working on their own independence in operation. The operation of these systems can be modified by manual switching process. The switching process takes place only there is a need for transmission line alteration and transmission line fault attendance period. The manual switching operation during fault occurrence period consumes lot of time for the trained person to reach the place and it may leads to severe damages to the transmission system, also it's a threat to human safety. In order to avoid such drawbacks circuit breakers and automatic trippers were installed to the transmission lines and distribution systems. The circuit breakers and trippers are able to switch off the system only after the fault observation in the transmission line system. The proposed artificial intelligence based management and control system consists of several sensor elements and wireless IoT transmission to predict and avoid the fault occurrence by monitoring the physical and atmosphere condition of the transmission and distribution line. The control structure fitted with the transmission line monitors the environment and line fault condition and the IoT transmission unit gives a possible communication from the remote monitoring system to the transmission line system for switching operations.
\end{abstract}

Keywords: Fault location, transmission line faults, IoT in transmission lines, transmission line sensors.

\section{Introduction}

Electrical power supplies are transmitted in very high voltages for avoiding transmission loss in the conducting lines. The high voltage transmission is achieved by employing a step up transformer to the line field. The step up transformers fixed at the end of power generating stations are called as power transformers. The power transformers step ups the voltage up to $440 \mathrm{KV}$ and makes the transmission as 3 phase 3 wire delta connection. The transmitted voltage losses its capacity due to long distance transmission in the power line. So that transmission substations are added to the transmission line to step up back the voltage to the desired range of $132 \mathrm{KV}$ for longer transmission. The transmission voltages are reduced to $11 \mathrm{KV}$ only when it is reaching nearer to the distribution area. The transformers fixed closer to the end user are called as secondary distribution transformers works to minimize the voltage to $440 \mathrm{~V} 3$ phase 4 wire

ISSN: 2582-3825 (online) 
Journal of Electronics and Informatics (2020)

Vol.02/ No. 02

Pages: 137-147

http://www.irojournals.com/iroei/

DOI: https://doi.org/10.36548/jei.2020.2.005

system for utilization. Figure 1 sketches the transmission and distribution process of power from generation station. The proposed management and control system is designed to monitor the secondary distribution zone for change and fault detection. The system monitors the following changes and faults in the electrical lines.

- Atmosphere weather changes

- Line to line fault

- Line to ground fault

- Open line fault

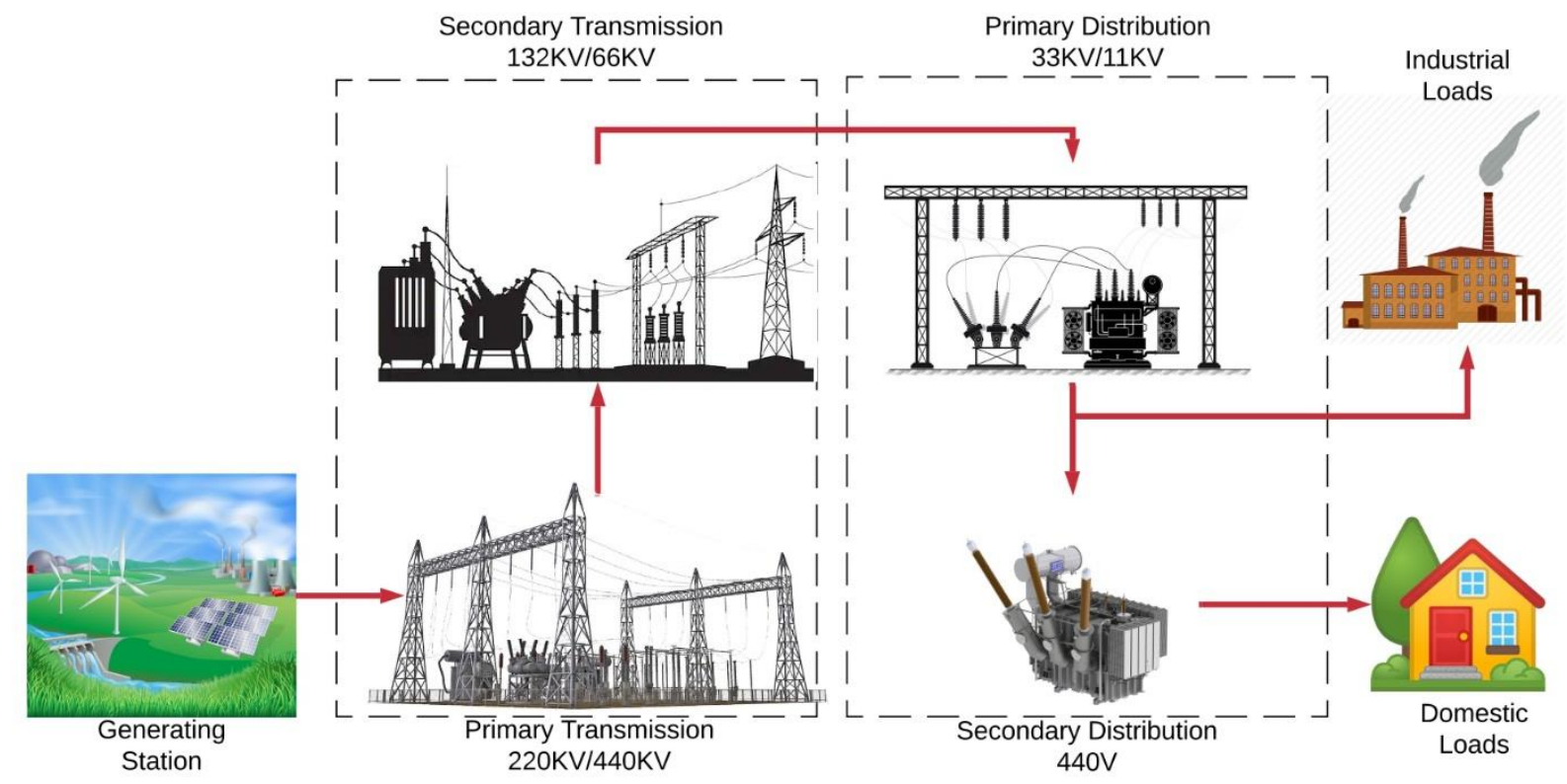

Figure 1. Power generation and transmission system.

\section{Related work}

As the electrical transmission lines are running for very long distance. It is very hard to locate the place of fault in the transmission lines. There are several methods were introduced to locate the right location of fault presence in the transmission line are discussed in this section. A back propagation based neural network design [1] was developed to locate the faults in transmission line. The neural network structure is trained with the existing fault data and accident data. The amount of data required to train the network

ISSN: 2582-3825 (online) 
Journal of Electronics and Informatics (2020)

Vol.02/ No. 02

Pages: $137-147$

http://www.irojournals.com/iroei/

DOI: https://doi.org/10.36548/jei.2020.2.005

model is generally difficult to collect. So that the type of fault occurred at a time is kept in to account for training the data continuously. The network structured design can perform with good accuracy when the model is trained with good number of sample data. A frequency dependent fault detection method [2] was proposed to identify faults in transmission line. The system was employed by monitoring the line voltage and line current continuously from transmission line for calculating the frequency movement in the lines as standard one. The difference in the standard frequency and the fault time frequency makes the system to understand the fault location in the transmission line. The IoT architecture for data transmission can improve the line monitoring process remotely. A trustable IoT system [3] was made to monitor the environment in agriculture fields with the help of sensors. The system was introduced to send the collected data information to the remote monitor through IoT data transmission. The information from the sensor are transmitted through secure nodes to avoid data loss.

An online technique for detecting faults in the transmission line [4] was framed by connecting the computer system at the transmission and receiver end of the power supply to monitor the voltage and current changes. The noticed current and voltages are carried to draw a locus diagram with the help of a specialized computer software for analyzing the supply performance. The voltage and current changes are varied with respect to load changes and faulty conditions are segregated to identify the faulty portion in the transmission line. A multi objective optimization technique [5] was structured to secure the collected data from IoT platform. The technique gives importance to security of the data received along with storage allocation and energy saving in IoT transmission platform. This avoids the bigger storage area necessity of collected data information. The collected information are stored in the temporary storage for immediate processing and forwards the unused data to the cloud storage for long term storage purpose. A positive sequence super imposed technique [6] was introduced to identify the fault locations by calculating the time difference from the auto closing time of the circuit. The difference in regular closing time of the circuit line with the faulty time was analyzed to find out the location area in the transmission line. For this operation the system is enough to be connected at one end of the transmission line.

An edge computing system on IoT applications [7] was designed to avoid occupying large storage space at the receiver end or cloud for processing. The edge computing computes the received parameters at the end location for saving storage space and time consumption in data transmission. The applied method also avoid unnecessary data loss due to reducing the transmission of huge data to the end user. A multi homing ant colony optimization with multipath distance vector algorithm [8] was proposed to improvise the efficiency of the IoT transmission in power management. The algorithm chooses a better path without traffic between the nodes to reach the destination successfully. The ant colony structure locates the better way for transmission of nodes, so that it avoids data drop and high energy utilization. A fault identification method on high voltage DC transmission line was introduced [9] based on three individual fuzzy logic systems. The first logic system is connected with the rectifier unit of the transmission line on both input and output line for finding the fault happened in AC or DC of the connected system. The second fuzzy system is connected to find out the faulty section in the AC or DC side of the system. The third fuzzy is fixed to identify the pole at where the fault is occurred in the transmission process.

ISSN: 2582-3825 (online) 
Journal of Electronics and Informatics (2020)

Vol.02/ No. 02

Pages: $137-147$

http://www.irojournals.com/iroei/

DOI: https://doi.org/10.36548/jei.2020.2.005

A single phase to ground fault detection algorithm [10] was made to locate the fault presence in the four circuit transmission systems. The dynamic characteristics of the fault signal is recorded with the help of wavelet analysis for sample data creation. The observed signals are continuously compared with the recorded signals through adaptive network based fuzzy system for finding the fault and its characteristics. A cloud computing system for big data analysis in IoT transmitted signal [11] was introduced to manage the huge data collected from medical applications. The data transmitted through IoT models are generally occupies huge space in the cloud due to continuous monitoring of the system environment. The big data analytics segments the data to corresponding receiver for faster communication between the end user and the storage portion. A fault location system on short branches transmission line [12] was developed by measuring the travelling waves generated on the transmission lines. There was three separate traveling wave recorders was fixed to the system one at end point, second at sectional point and third at pole point. The wave changes with time variance in the transmission line is observed to analyze fault locations accurately. The recorded wave changes is designed to compare with the theoretical wave predicted in the simulation for faster achievements.

An IoT based fault location system in power lines [13] was introduced to observe the changes in the transmission from remote locations. The transmission lines are designed with several sensors in the transmission areas and the sensed signals are transmitted through a network layer to the application layer for computing the data for fault location identification. An intelligent cloud platform was fixed between the application layer and network layer to transmit only the necessary and emergency information to the application layer for alarming and fault analysis. A secure algorithm based steganography technology [14] was proposed to encrypt the transmitted data to the end user securely. This technology assures the transmitted data from misuse and manipulation. The forwarded information are able to read out only by the secured user by encrypting data through secure key. This improves the reliability of the information sharing in IoT systems. An adaptive network based hybrid fuzzy interface system [15] was designed to monitor the power quality in five different layers of the transmission lines. The power quality is measured by several sensors fixed in the transmission line and the measured parameters are calculated to develop a mathematical model for comparison. The observed data can be used for training the network model and validation. The system is also compared with ANN and fuzzy algorithm for finding its performance betterment among the other algorithms.

\section{Proposed work}

The artificial intelligence based distribution line management and control system is proposed to avoid transmission lines from damages and faults. The fault presence in the transmission lines are analyzed by the voltage and current changes observed by the sensors fixed over the transmission lines. Figure 2 explores the overall structure of the proposed model. The model consists of three portion. One at primary distribution station, next at secondary distribution station and the third at end user distribution place. The end user distribution portion acts as a sensor layer for monitoring the supply fluctuations by the help of sensors fixed

ISSN: 2582-3825 (online) 
Journal of Electronics and Informatics (2020)

Vol.02/ No. 02

Pages: 137-147

http://www.irojournals.com/iroei/

DOI: https://doi.org/10.36548/jei.2020.2.005

directly over the transmission lines. The sensed data are transmitted to the secondary distribution for minor problem rectification and to primary distribution station for major problem rectification.

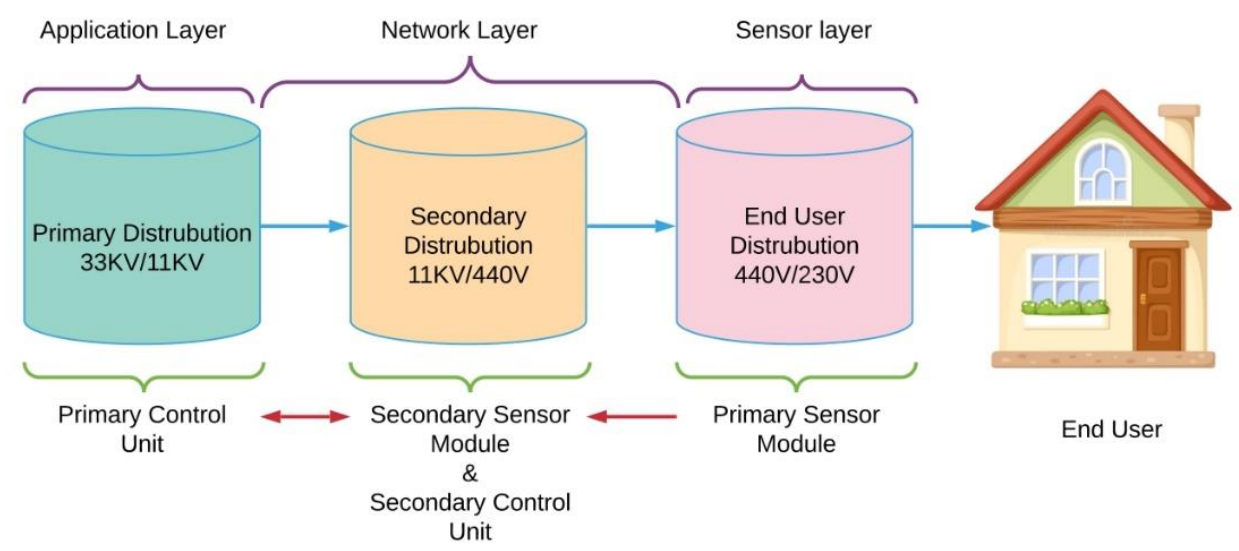

Figure 2. General structure of the proposed system

The difference in problems are analyzed by the microcontroller fixed to the primary sensor module. Figure 3 indicates the structures employed in the primary sensor module for monitoring and data transmission purpose. The voltage sensor and current sensor are fixed directly to the transmission line for measurements. The wind sensor and weather sensor are fixed at the poles of transmission line for observing the environment condition. The wind sensor is helpful in estimating the shagging of transmission lines between each other during heavy wind condition. The weather sensor is a simple rain sensor fixed to observe the climatic changes in the transmission field. The sensed values are analyzed by the microcontroller fixed in the module. The microcontroller enables the IoT transmission only when there is a need to transmit the data at critical condition.

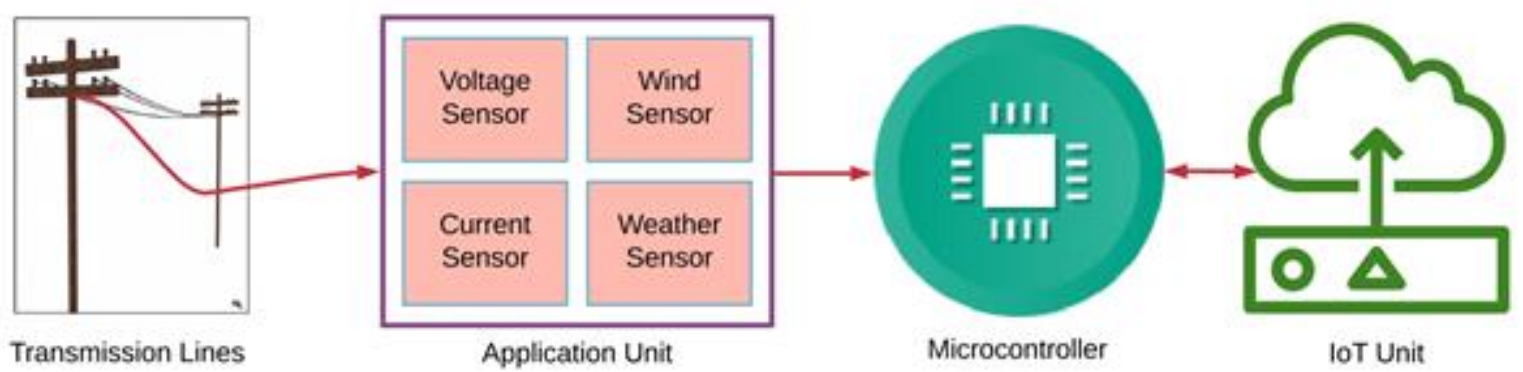

Figure 3. Structure of primary sensor module. 141

ISSN: 2582-3825 (online) 
Journal of Electronics and Informatics (2020)

Vol.02/ No. 02

Pages: 137-147

http://www.irojournals.com/iroei/

DOI: https://doi.org/10.36548/jei.2020.2.005

The data transmitted from the primary sensor module is received by the secondary sensor and control unit for analyzing the data received from many group of primary sensor modules connected the same area. The secondary sensor and control unit is a secondary distribution station connected with many user areas for power supply distribution. The microcontroller fixed in the secondary module analyses the data performs action accordingly. Figure 4 explicates the arrangements of units involved in the module. Addition to the primary sensor module, the microcontroller is connected with drivers and circuit breakers for enabling and disabling the power operation between the transmission lines. When the problem from all the connected area arises at the same time, the secondary module transmit the information to the primary control unit for analysis and decision making. The secondary module can be controlled and managed by the primary control unit from its regular architecture connected to the system.

The primary control unit is enabled with a circuit analyzer software model for recording and analyzing the faulty conditions in the distribution area. The software is also enabled with digital controllers to take decision by the microcontroller's artificial intelligence. The transmission lines and circuit breakers of the distributions systems are connected through a relay circuit for operations. The power supply to the microcontrollers and other modules are directly taken from the transmission lines by stepping it down through a normal $230 \mathrm{~V} / 12 \mathrm{~V}$ transformers. The sensor modules are also added with a battery source for monitoring the distribution scenario in off load conditions. The voltage changes in the transmission lines during line to line fault, line to ground fault and open line fault results in variable voltage and current changes. The microcontroller analyses the fault with respect to the changes observed by the sensors connected to the transmission lines.

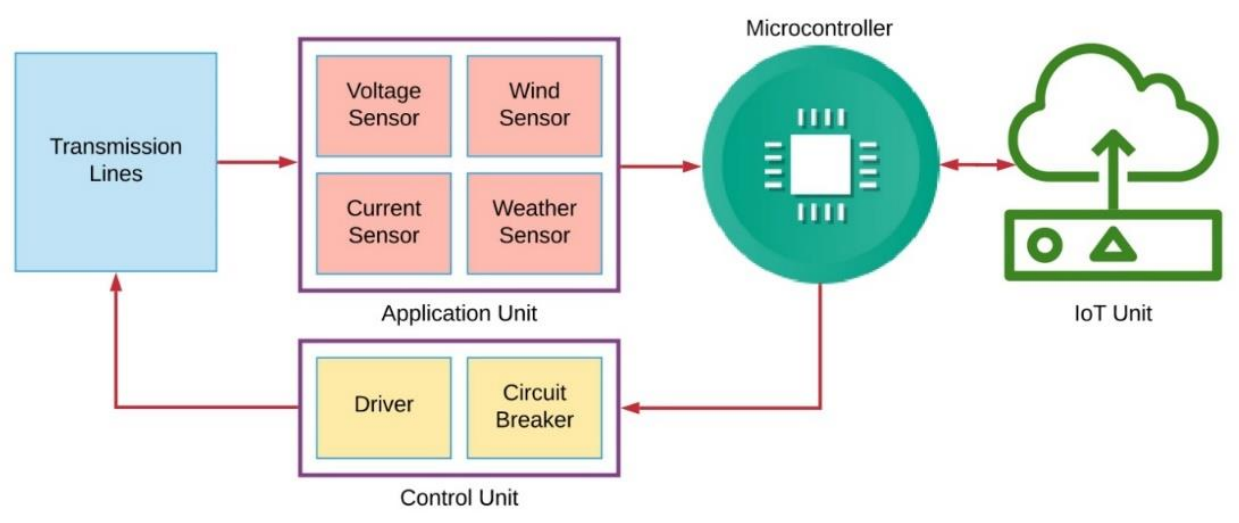

Figure 4. Structure of secondary sensor and control unit.

ISSN: 2582-3825 (online) 


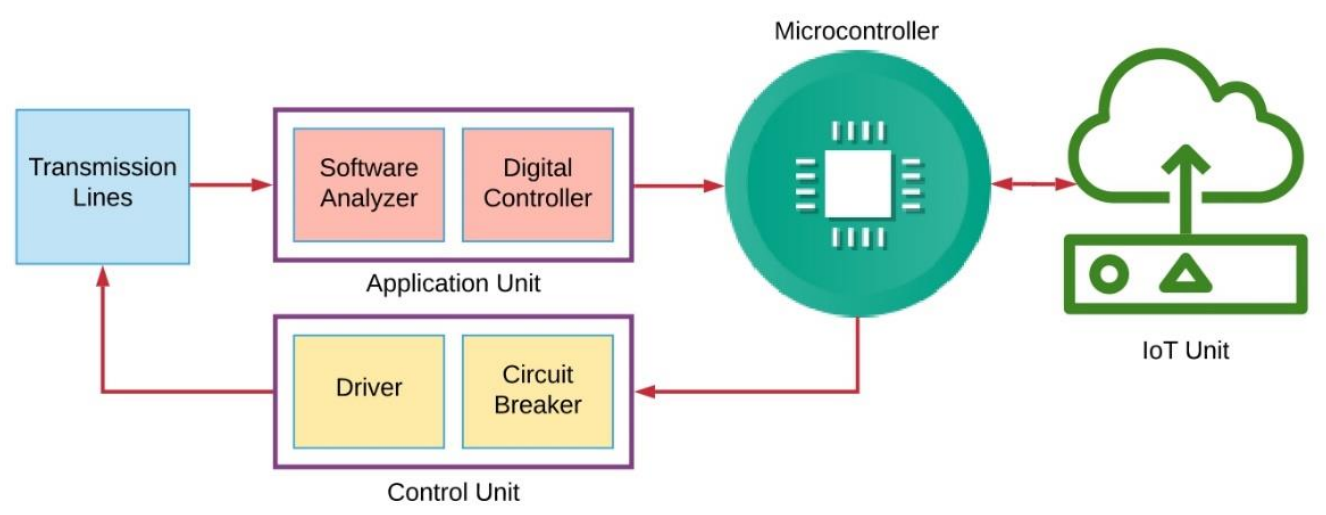

Figure 5. Structure of primary control unit.

\section{Results and Discussion}

The proposed architecture is simulated and the results on voltage variations are observed to find out the faults in the transmission lines. Figure 6 indicates the line to line fault observation reading from a four wire three phase transmission system. The voltage across the phases and phase to neutral is observed continuously by the microcontroller and with respect to the changes observation, the decision on transmitted signal to the control units are varied. The voltage between the phases gets irrelevant high voltages when a transmission line contacts with the other phase. So that the decision on line to line fault is observed and forwarded to the control unit. The decision of signal from secondary control unit to primary control is about the number of primary sensor units are affected in the system due to fault and climatic conditions. 
Journal of Electronics and Informatics (2020)

Vol.02/ No. 02

Pages: 137-147

http://www.irojournals.com/iroei/

DOI: https://doi.org/10.36548/jei.2020.2.005

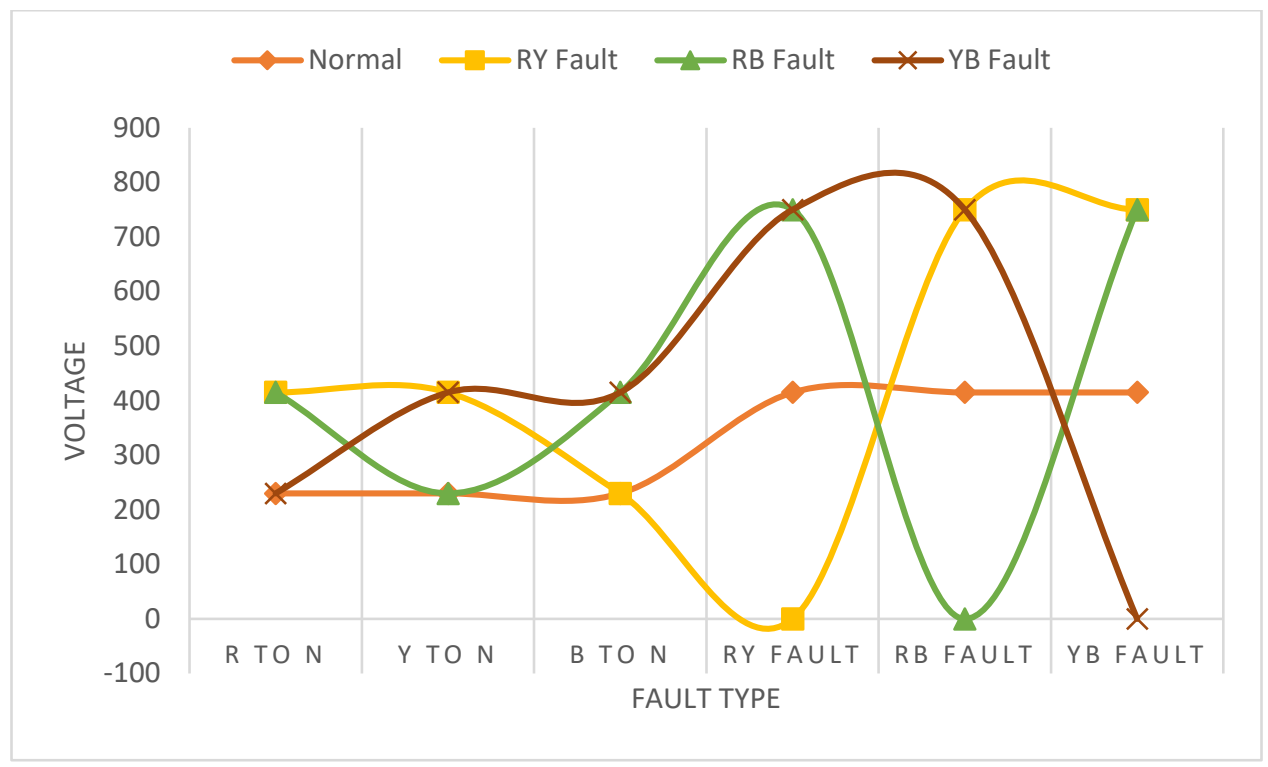

Figure 6. Line to line fault analysis.



Figure 7. Line open and line to ground fault.

The line to ground fault and line open faults are also analyzed in the proposed model by observing the voltage changes captured by the voltage sensors. Figure 7 indicates the open line fault and line 
Journal of Electronics and Informatics (2020)

Vol.02/ No. 02

Pages: 137-147

http://www.irojournals.com/iroei/

DOI: https://doi.org/10.36548/jei.2020.2.005

to ground fault. The line open faults can be observed directly when the voltage between that particular phases to neutral becomes zero. Similarly the voltage between some phase to neutral shows lesser voltage when the phase is contacted directly with a ground. The voltage changes are taken into account for microcontroller decision of data transmission.

The weather changes are observed through a comparator circuit for microcontroller observation. The rain sensor gives high output when there is no rain and the voltage gets reduce when there is rain. The amount of rainfall falling over the sensor reduces the output voltage from the sensor. The sensitivity of the sensor can be modified by adjusting the comparator potentiometer. Figure 8 gives the output voltage from the rain sensor and wind sensor with respect to various climatic difference. The wind sensor works opposite to the rain sensor, generates high voltage when there is heavy wind and produce less voltage when the wind level is very low. Both of these sensor requires comparator to connect with microcontroller. The comparators need to be connect with the analog input of the microcontroller for measuring the analog variance from the connected sensors.

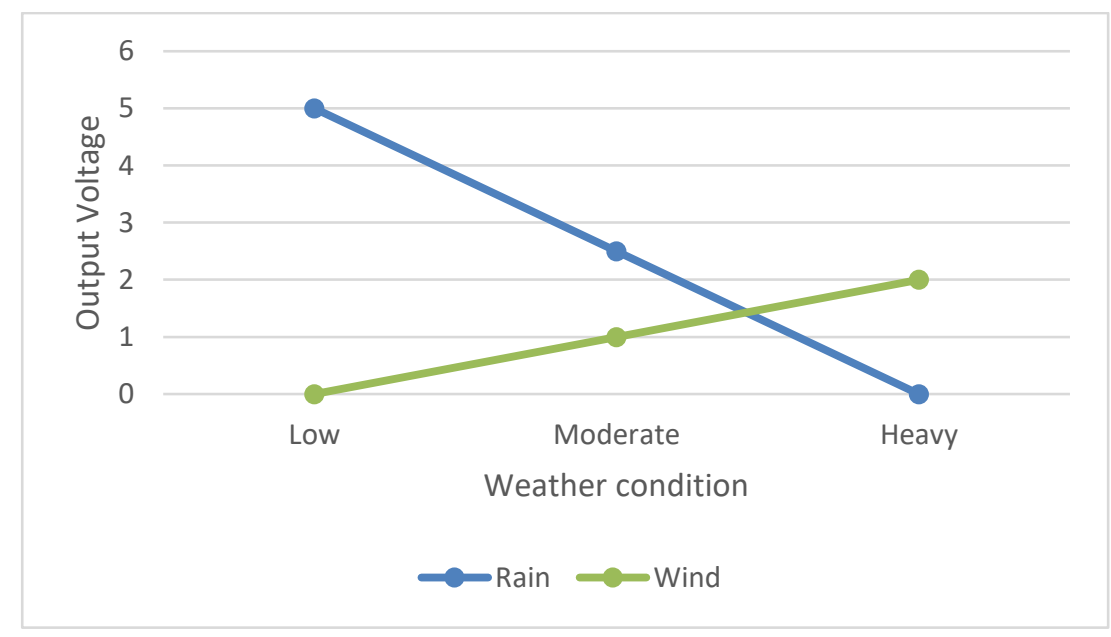

Figure 8. Output of rain and wind sensor.

\section{Conclusion}

The proposed artificial intelligence based distribution system management and control system controls the transmission line system independently with respect to the voltage observations from the sensor devices. The IoT signal transmission from sensor module to control module is carried

ISSN: 2582-3825 (online) 
Journal of Electronics and Informatics (2020)

Vol.02/ No. 02

Pages: $137-147$

http://www.irojournals.com/iroei/

DOI: https://doi.org/10.36548/jei.2020.2.005

with 433Mhz IoT system. The proposed system can be combined with a personalized network model for secure and desired data transmission. The proposed model eliminates the time consumption needed for switching control of transformers and circuit breakers. The model also stores the fault condition parameters for future analysis for expansion of the transmission line system. The digital controller presence in the software module is also helpful for remote operation of the secondary distribution system.

\section{References}

[1] Kou, Ran, and Yuhong Wang. "Transmission Line Fault Identification Based on BP Neural Network." In 2019 IEEE Innovative Smart Grid Technologies-Asia (ISGT Asia), pp. 991-994. IEEE, 2019.

[2] Yang, Liming, Fufeng Chen, Mingjun Xue, Yuping Li, Shi Chen, and Lei Zou. "A Novel Fault Location Method for HVDC Transmission Lines." In 2019 IEEE PES GTD Grand International Conference and Exposition Asia (GTD Asia), pp. 341-346. IEEE, 2019.

[3] Haoxiang, Wang. "Trust management of communication architectures of internet of things." Journal of trends in Computer Science and Smart technology (TCSST) 1, no. 02 (2019): 121-130.

[4] Abu-Siada, A., and Saif Mir. "A new on-line technique to identify fault location within long transmission lines." Engineering Failure Analysis 105 (2019): 52-64.

[5] Mugunthan, S. R. "Security and privacy preserving of sensor data localization based on internet of things." Journal of ISMAC 1, no. 02 (2019): 81-91.

[6] Ji, Liang, Xiaojie Tao, Yang Fu, Yong Fu, Yang Mi, and Zhenkun Li. "A New Single Ended Fault Location Method for Transmission Line Based on Positive Sequence Superimposed Network During Auto-Reclosing." IEEE Transactions on Power Delivery 34, no. 3 (2019): 1019-1029.

[7] Sivaganesan, D. "Design and development ai-enabled edge computing for intelligent-iot applications." Journal of trends in Computer Science and Smart technology (TCSST) 1, no. 02 (2019): 84-94.

[8] Krishnaraj, N., and S. Smys. "A Multihoming ACO-MDV Routing for Maximum Power Efficiency in an IoT Environment." Wireless Personal Communications 109, no. 1 (2019): 243-256.

[9] Agarwal, S., A. Swetapadma, C. Panigrahi, and A. Dasgupta. "A method for fault section identification in High voltage direct current transmission lines using one End measurements." Electric Power Systems Research 172 (2019): 140-151.

[10] Khaleghi, Ali, and Mahmoud Oukati Sadegh. "Single-Phase Fault Location in Four-Circuit Transmission Lines Based on Wavelet Analysis Using ANFIS." Journal of Electrical Engineering \& Technology 14, no. 4 (2019): 1577-1584.

[11] Smys, S., and Jennifer S. Raj. "Internet of things and big data analytics for health care with cloud computing." Journal of Information Technology 1, no. 01 (2019): 9-18.

ISSN: 2582-3825 (online) 
Journal of Electronics and Informatics (2020)

Vol.02/ No. 02

Pages: 137-147

http://www.irojournals.com/iroei/

DOI: https://doi.org/10.36548/jei.2020.2.005

[12] Peng, Nan, Lutian Zhou, Rui Liang, and Haoyuan Xu. "Fault location of transmission lines connecting with short branches based on polarity and arrival time of asynchronously recorded traveling waves." Electric Power Systems Research 169 (2019): 184-194.

[13] Kong, Xiangyu, Yong Xu, Zaibin Jiao, Delong Dong, Xiaoxiao Yuan, and Shupeng Li. "Fault Location Technology for Power System Based on Information about the Power Internet of Things." IEEE Transactions on Industrial Informatics (2019).

[14] Vinothkanna, Mr R. "A secure steganography creation algorithm for multiple file formats." Journal of Innovative Image Processing (JIIP) 1, no. 01 (2019): 20-30.

[15] Zhang, Yantian, Haoxiang Wang, and Yanzhao Xie. "An intelligent hybrid model for power flow optimization in the cloud-IOT electrical distribution network." Cluster Computing 22, no. 6 (2019): 13109-13118.

\section{Authors Biography}

Dr. D. Nirmal is currently working as Associate Professor, in Department of Electrical sciences, Karunya University, Karunya Nagar, Coimbatore, Tamil Nadu, India. His research area of interest are VLSI, NanoElectrical Automation, Electronics, information systems and technology in the areas of innovative system designs, architectures, algorithms and applications.

ISSN: 2582-3825 (online) 